\title{
As relações étnico-raciais na Literatura Infantil e Juvenil ${ }^{1}$
}

\section{Ethnic-racial relations in children's and young adult literature}

\author{
Débora Cristina de Araujo*
}

\begin{abstract}
RESUMO
Este artigo reúne a síntese dos resultados de pesquisas sobre a produção literária infantil e juvenil na dimensão das relações étnico-raciais. Foram ao todo 13 estudos em nível de mestrado e doutorado, captados no levantamento para o projeto "Educação das Relações Étnico-Raciais: o estado da arte". Trata-se de pesquisas da pós-graduação em Educação, desenvolvidas entre os anos 2003 a 2014. Por meio da análise predominantemente qualitativa, foi possível estabelecer duas categorias: a "análise literária", reunindo os estudos que investigaram uma ou mais obras de um mesmo autor e cuja característica em comum é a interface com contextos históricos e sociológicos, em especial do passado; e a "escolarização da literatura", agrupando as pesquisas que, no contexto escolar, investigaram a presença, leitura e interpretação de obras literárias infantis e juvenis. Desta segunda categoria, novas subdivisões foram definidas a partir de elementos característicos próprios. Os dados quantitativos possibilitaram identificar os locais predominantes de produção acadêmica com tais temáticas, bem como os anos mais produtivos no campo. Via de regra, os estudos indicaram um consenso sobre mudanças, ainda que diminutas, na representação de personagens negras a partir de publicações literárias mais recentes, embora negras e negros ainda sejam minoria como personagens no universo literário infantil e juvenil de modo geral. E entre
\end{abstract}

1 Este artigo é parte do resultado da pesquisa que compôs o projeto "Educação das Relações Étnico-Raciais: o estado da arte", financiado pela Coordenação de Aperfeiçoamento de Pessoal de Nível Superior (CAPES), Conselho Nacional de Desenvolvimento Científico e Tecnológico (CNPq), Fundação Araucária de Apoio do Desenvolvimento Científico e Tecnológico do Paraná e Secretaria de Educação Continuada, Alfabetização, Diversidade e Inclusão (SECADI/MEC).

*Universidade Federal do Espírito Santo. Centro de Educação. Vitória, Espírito Santo, Brasil. E-mail: debora.c.araujo@ufes.br. ORCID: https://orcid.org/0000-0001-8442-3366 
as lacunas identificadas por este levantamento está o pouco investimento de estudos na recepção da leitura literária, em especial com crianças pequenas.

Palavras-chave: Literatura Infantil e Juvenil. Personagens negras. Teses e dissertações. Escolarização da literatura.

\begin{abstract}
This article brings together the synthesis of research results on children's and young people's literary production in the dimension of ethnic-racial relations. A total of 13 master's and doctoral studies were identified, captured in the survey for the project "Education of Ethnic-Racial Relations: The State of Art". These are postgraduate research in education, developed between 2003 and 2014. Through the predominantly qualitative analysis, it was possible to establish two categories: the "literary analysis", which brought together studies that investigated one or more works of the same author and whose characteristic in common is the interface with historical and sociological contexts, especially of the past; and the "schooling of literature", grouping the researches that, in the school context, investigated the presence, reading and interpretation of children's and juvenile literary works. From this second category, new subdivisions were defined by means of their own characteristic elements. The quantitative data allowed to identify the predominant places of academic production with such themes, as well as the most productive years in the field. As a rule, the studies have indicated a consensus about changes, albeit diminutive, in the representation of black characters from more recent literary publications, although blacks are still a minority as characters in the literary universe for children and youth in general. And among the gaps identified by this survey is the little investment of studies in the reception of literary reading, especially with small children.
\end{abstract}

Keywords: Children and Youth Literature. Black characters. Theses and Dissertations. Schooling of literature.

\title{
Reflexões iniciais
}

Desde o surgimento do gênero literário endereçado à infância e juventude brasileira, denominado neste texto de Literatura Infantil e Juvenil (LIJ), vem sendo empreendida uma busca por produções que tenham assumido a valorização e o reconhecimento da diversidade humana como elemento agregador à qualidade artística de suas obras. Assim, tais estudos consideram que entre os 
critérios que definem a qualidade estético-literária de um livro está, portanto, o reconhecimento e a afirmação dos grupos humanos em sua diversidade cultural, social, étnica e racial.

Se antes essa busca era assumida por poucas pesquisadoras e pesquisadores, hoje já não se pode mais afirmar isso. Uma prova são os estudos que serão apresentados neste texto que e, embora com características nem sempre convergentes sobre os resultados, são investigações que intentaram, cada uma à sua maneira, analisar como a Literatura Infantil e Juvenil vem representando os grupos humanos, em especial uma significativa parcela da população que foi histórica e simbolicamente estigmatizada por sua origem africana.

Mas nem todos os estudos, sobretudo os referenciais da teoria literária, convergem sobre o reconhecimento do nível de importância de personagens ne$\operatorname{gras}^{2}$ nesse gênero literário. Tais divergências acionam elementos significativos acerca das formas de interpretação do racismo na sociedade brasileira. Um grupo hegemônico da teoria literária clássica tende a identificar, em fases anteriores da LIJ, um avanço na representação de personagens negras, por reconhecerem que nos primórdios dessa produção literária não havia sequer tais representações. Por outro lado, um número crescente de estudos e de autoras vem apontando que mesmo em períodos considerados como "vanguardistas" (por visibilizarem personagens negras), as condições de estereotipia e inferioridade se mantiveram.

E é possível caracterizar essa dicotomia tomando algumas autoras referenciais: Nely Novaes Coelho, Fúlvia Rosemberg, Maria Cristina Soares Gouvêa e Maria Anória de Jesus Oliveira. Coelho (1990) propôs uma "divisão histórico-literária" desse gênero literário no Brasil, tomando Monteiro Lobato como marco. Para tanto, a autora estabeleceu três grandes fases: a primeira, chamada de "Precursora ou pré-lobatiana", que vai de 1808 a 1919, e que tem como principal característica a presença de narrativas orais de origem europeia com forte tendência ao moralismo, ao nacionalismo e ao didatismo; a segunda fase foi denominada de "Moderna ou período lobatiano", entre as décadas de 1920 a 1970, cujas características relacionam-se à presença do maravilhoso e da desmistificação da moral tradicional e da verdade individual; já a terceira fase, chamada pela autora de "Pós-Moderna ou período pós-lobatiano", seria a literatura produzida na contemporaneidade (desde 1970), em que predominariam o experimentalismo com a linguagem e com a imagem por meio de uma literatura inquietante e questionadora das convenções e valores da sociedade.

Embora essas três fases sejam importantes demarcadores, para Oliveira, M.A.J. (2010) há objeções quando, por exemplo, a análise de Coelho não inclui

2 Neste artigo, o vocábulo "personagem" será generalizado no feminino, como era a origem etimológica dessa palavra. Nas citações, será mantido conforme a grafia adotada pela autora ou autor. 
o racismo como categoria componente da produção literária em cada uma das fases ou quando, em outra proposta de divisão da literatura entre Tradicional e Novo, ao tematizar o Tradicional, tal autora correlacione o processo de escravização da população negra no Brasil a uma "força indispensável ao progresso de qualquer grupo social” (COELHO, 2000, p. 23). Para Oliveira, M.A.J. (2010, p. 52), em nota de rodapé $n^{\circ} 48$ :

Apesar de Coelho se referir à escravização humana como 'um processo de Injustiça Humana e Social que até os nossos tempos não pode ser totalmente extirpada', antes, porém, sendo a 'raça branca a vencedora', ao que diríamos, beneficiada social e economicamente até a atualidade (MOORE, 2007), ela, por outro lado, a entende como a 'força indispensável ao progresso de qualquer grupo social'. Essa afirmação mereceria maiores explanações ou, no mínimo, a problematização do sistema atroz que ceifou a vida de um contingente incalculável de pessoas negras e ameríndias ao longo de quase quatro séculos, desencadeando uma série de complexidades e desigualdades até os dias de hoje. O racismo é um deles. Tanto é que no limiar do século XXI discutimos, ainda, a urgência da reparação social para com os grupos sociais vilipendiados e usurpados de suas terras: os descendentes de africanos e os ameríndios (OLIVEIRA, M.A.J., 2010, p. 52).

A ideia de tradição em Coelho é retomada sob outra perspectiva: para ressaltar a atuação dessa tradição a fim de "expressar um olhar preconceituoso e inferiorizado face ao segmento negro, recortando-se e privilegiando a ideia de 'vencidos' pelo segmento branco, preterindo-se as resistências, as lutas, conquistas” (OLIVEIRA, M.A.J., 2010, p. 53). Assim, a literatura endereçada ao público infantil e juvenil estaria marcadamente, desde seus primórdios, comprometida com a perpetuação de relações de dominação racial, tendo a população negra como coadjuvante da história desse gênero literário.

E tal processo se manteve nas demais fases. Observando a segunda fase, chamada Moderna, tomo a argumentação de Gouvêa (2005) como alerta para $\mathrm{o}$ fato de que o aumento de personagens negras nas tramas nada se relacionou com maior qualidade no tratamento direcionado a elas. Pelo contrário, estigmas e estereótipos foram criados ou reforçados. Destaca-se, por exemplo, a recorrência de personagens negras idosas, mulheres e homens, sendo retratadas/os como "contadoras/es de histórias", "agentes socializadores das crianças brancas, numa posição de servidão que revela a continuidade com o modelo escravocrata" (GOUVÊA, 2005, p. 84) ou, ainda, como "pretos e pretas velhas", detentores/as 
de um saber mítico, fazendo "sobreviver suas tradições, como as práticas religiosas, vistas como feitiçaria pelos personagens brancos" (GOUVÊA, 2005, p. 86). Nessa caracterização, por vezes o velho ou a velha tinham seu intelecto associado à criança pequena, "como se ambos estivessem no mesmo nível de desenvolvimento cognitivo" (GOUVÊA, 2005, p. 87). Mas não somente como velhos é que as personagens negras se faziam presentes de modo estereotipado nas tramas: era, sobretudo, por meio do corpo animalizado.

Fica clara uma animalização do negro, na medida em que a descrição do seu corpo colocava-o entre o corpo animal e o corpo do homem branco. Os textos, na verdade, reproduziam uma representação que, historicamente, fez-se presente no campo científico, ao final do século XIX, que situava o negro, no interior da cadeia evolutiva, num patamar entre o homem branco e as demais espécies [...] (GOUVÊA, 2005, p. 88).

Oliveira, M.A.J. (2010) não nega a condição da população negra na sociedade brasileira da época, em um período ainda muito recente desde o término da escravização oficial. Contudo, interroga sobre a cristalização desse momento histórico na literatura endereçada à criança.

Então, se Coelho compreende que a literatura infantil refletiu 'uma situação social concreta', a escravização, cabe não esquecer que tal literatura priorizou o ponto de vista do grupo hegemônico. Desse modo, cristalizou um olhar sobre os escravizados, sobretudo, como seres passiveis à comiseração e passivos, sem reação contra o sistema opressor. (OLIVEIRA, M.A.J., 2010, p. 55).

A autora questiona, nesse panorama, não só a recorrência de narrativas que rememoram crueldades e suplícios contra personagens negras - semelhantes ao período da escravização -, mas também "a ausência de outros pontos de vista, afinal, não podemos esquecer que as resistências negras, naquela conjuntura escravagista, consistiram em variadas maneiras de se rebelar e reagir contra o sistema opressor" (OLIVEIRA, M.A.J., 2010, p. 55-56).

E tomando a perspectiva de Rosemberg (1985) como outro referencial analítico do período, mesmo na transição entre a segunda e a terceira fase - chamada de Pós-Moderna, por Coelho (mas, concordando com Oliveira aqui também será 
chamada de Contemporânea) -, as condições de representação das personagens negras pouco mudaram. Em uma pesquisa que reuniu análise de 168 livros endereçados a crianças e jovens e editados entre 1955 e 1975, entre as principais características identificadas destacam-se: associação do ser negro com castigo e com feiura; associação, pela cor, com maldade, tragédia, sujeira, escravidão; correlação de personagens negras com profissões socialmente desvalorizadas; personagens brancas apresentadas como representante da espécie; a mulher negra presa ao estereótipo de empregada doméstica (ROSEMBERG, 1985).

Assim, constata Oliveira, M.A.J. (2010, p. 57), que tanto na primeira, segunda ou no limiar da fase contemporânea, "tomando como base a demarcação temporal de Coelho (2003), [a Literatura Infantil e Juvenil] não deixou de reforçar a inferiorização do segmento negro e a valoração do branco na literatura infanto-juvenil”.

E desse panorama, complexo e dicotômico brevemente aqui apresentado, muitas das pesquisas a seguir se ampararam para analisar contextos mais recentes da produção literária infantil e juvenil e sua interface com as relações étnico-raciais, em especial entre os grupos negro e branco. São estudos em nível de mestrado e de doutorado captados no projeto "Educação das Relações Étnico-Raciais: o estado da arte", que visou realizar uma ampla investigação do conhecimento produzido no Brasil sobre Educação das Relações Étnico-Raciais (ERER) no período de 2003 a 2014. Trata-se de 13 teses e dissertações do campo da Educação que investiram o olhar sobre a Literatura Infantil e Juvenil na dimensão das relações étnico-raciais ${ }^{3}$.

\section{O campo stricto sensu da LIJ e as relações étnico-raciais}

Dadas as características das três teses e das 10 dissertações que compõem o corpus de análise deste estudo, foi possível organizá-las em duas grandes categorias: "análise literária" e "escolarização da leitura". A segunda delas apresenta, por sua vez, particularidades que levaram a subdivisões, conforme será apresentado no decorrer desta seção. É importante ressaltar que alguns dos estudos terão menor destaque conforme se afastem da Literatura Infantil e Juvenil. São pesquisas que ficaram no limitar deste gênero ao tematizarem

3 No estudo completo da categoria Literatura Infantil e Juvenil do Projeto "Educação das Relações Étnico-Raciais: o estado da arte", também foram captados 27 artigos que, em função dos limites deste artigo, não serão apresentados aqui. 
obras que eventualmente ocupam o universo de leitura juvenil, mas que, na sua produção original, eram endereçadas ao público adulto; além disso, apresentam uma interface com contextos históricos e sociológicos, em especial do passado. Apenas nos casos em que a obra com tal característica estiver contextualizada no ambiente escolar - portanto, escolarizada - terá uma apresentação com maiores detalhes.

$\mathrm{Na}$ "análise literária" encontram-se estudos que focalizaram um ou mais obras de um mesmo autor, como é o caso do estudo de Fernanda de Jesus Ferreira (2012) que investigou, em livros, discursos e cartas de José de Alencar, suas posições públicas acerca da escolarização de escravizados. Na imersão analítica sobre os textos do autor, Ferreira (2012) identificou dicotomias entre as reflexões acionadas nas obras e nos demais documentos:

Em relação aos escravizados, o autor revela, em seus discursos políticos, que havia necessidade de educá-los, mas os meios para tal empreendimento não passavam pelas conformações do conhecimento das letras, ironicamente possível em Machado de Assis. Já em sua obra literária, Alencar demonstra a partir do enredo e do desfecho das personagens escravas na história, que a sociedade não tinha proposta alguma para os escravizados futuramente se integrarem como 'cidadãos inteligentes'. (FERREIRA, 2012, p. 151).

Com a mesma característica, de investigação de um autor, nesse caso de Lima Barreto, desenvolveu-se a pesquisa de Jomar Ricardo da Silva (2007), cujo objetivo foi de compreender "através de indícios presentes na obra deste escritor, como se efetivava a educação das mulheres, no início do século XX, para a consecução da diferenciação histórica das relações de gênero" (SILVA, 2007, p. 8). Por meio da análise de contos e romances desse escritor, Silva (2007) identificou que o engajamento de Lima Barreto para questões sociais de modo geral também se refletiu nas questões de gênero, evidenciando sua capacidade analítica dos problemas contemporâneos.

Um estudo em particular, de Lilian Cavalcanti Fernandes Vieira (2012), analisou a questão da identidade e cultura de matriz africana por meio da obra de um autor afro-caribenho: Derek Walcott. E, ainda, outro estudo classificado nesta categoria diferenciou-se dos demais: a tese de Roselete Fagundes de Aviz de Souza (2012) que, embora tenha analisado obras de autores e autoras negras africanas ou da diáspora (Zora Neale Hurston, Paulina Chiziane, Ungulani Ba Ka Khossa), teve como objetivo investigar elementos subjetivos que envolvem reflexões literárias, culturais, filosóficas e estéticas. 
Já o estudo de Luciana Araujo Figueiredo (2010) teve como objetivo analisar como as relações entre crianças negras e não negras foram construídas ao longo do tempo no Brasil, via obras literárias. Para tanto, a autora analisou 10 livros de Literatura ou de Sociologia publicados em diversos períodos da história do Brasil. Em seus resultados, Figueiredo identificou que na produção contemporânea houve um aumento na qualidade das representações de criança negra, com a valorização de traços e símbolos da cultura negra e melhor trato de temáticas envolvendo o racismo e o preconceito. Sua interpretação é que tal produção, em comparação com as obras mais antigas, seja influência das lutas sociais por representações sociais mais positivas.

$\mathrm{Na}$ "escolarização da literatura", maior das duas categorias, encontram-se estudos que se relacionam com o processo de imersão de obras literárias no contexto escolar. A expressão que intitula tal categoria nasce da proposição de Magda Soares (2006, p. 21) de que a literatura "ao se tornar 'saber escolar', se escolariza". No entanto, concordando com a asseveração da autora, é necessário atenção aos modos pelos quais tal processo de escolarização se opera para que, ao transpor a produção literária para o ambiente escolar, ela não se desfigure, desvirtue ou falseie (SOARES, 2006). E, nesse sentido, as pesquisas aqui classificadas refletiram sobre tal problemática e acrescentaram elementos acerca da qualidade estético-literária a partir da diversidade étnico-racial. Para tais estudos não é possível considerar que uma obra literária dotada de preconceitos ou estereótipos raciais contribua para a ampliação de referenciais literários, artísticos e culturais do público leitor. Todos alertaram, em maior ou menor medida, que a valorização de matrizes literárias para além do cânone (que na LIJ é essencialmente monocultural) é base para a formação de qualquer leitor. E nessa busca, algumas pesquisas investiram em evidenciar o racismo presente nas obras canônicas, outra em propor obras que tematizam a cultura africana e afro-brasileira em perspectivas positivas, e ainda outras que analisaram os contextos de recepção de leituras de obras por parte do público leitor. Estamos diante, portanto, de uma nova divisão da categoria "escolarização da literatura", conforme será discutido na próxima seção.

\section{A literatura escolarizada}

O primeiro grupo dessa categoria de escolarização da literatura reúne estudos que investigaram em acervos (de bibliotecas escolares e/ou programas de distribuição de livros) como personagens negras são representadas. O estudo de Oliveira (2003), por exemplo, analisou 12 títulos de "autores consagrados" que 
foram publicados entre 1979 a 1989, com o objetivo de apresentar categorias analíticas que evidenciem a caracterização das personagens negras em tais obras e verificar se houve inovações de modo que houvesse um rompimento com a estereotipia anteriormente captada por pesquisas como a de Rosemberg (1985). A autora identificou inovações no período analisado, pelo fato de personagens negras assumirem em maior recorrência o protagonismo dos enredos, "com o propósito de denunciar a pobreza, o preconceito racial, e em enaltecer os seus traços físicos" (OLIVEIRA, 2003, p. 10). Contudo, as estratégias utilizadas na construção de tais personagens acabaram por reificar estereótipos, já que a maioria delas foi associada à pobreza, com trajetórias de abandono ou orfandade, experienciando situações de violência física ou verbal ou, ainda, enaltecidas "pelos atributos físicos e/ou intelectuais, com vista à democracia racial" (OLIVEIRA, 2003, p. 10). Apenas uma das obras de sua amostra, "A cor da ternura", de Geni Guimarães, conseguiu romper com esse ciclo de estereótipos e dar "um salto de qualidade ao exprimir o universo imerso em fantasia e ludicidade da protagonista" (OLIVEIRA, 2003, p. 10).

A pesquisa de Ana Carolina Lopes Venâncio (2009) investigou um acervo de 20 obras do Programa Nacional de Biblioteca da Escola (PNBE) de 2008 voltada para estudantes do $1^{\circ}$ ao $5^{\circ}$ ano do Ensino Fundamental. O objetivo da autora foi analisar, com base nos eixos de idade, gênero, raça e relativos à deficiência, como "a literatura infanto-juvenil pode, ao criar personagens e dotá-los de características e atributos, tanto atuar de forma a promover a diversidade como manter modelos e padrões de humanidade que venham a reforçar estigmas e preconceitos" (VENÂNCIO, 2009, p. 12). Os resultados indicaram quantitativamente que houve uma diminuição na dicotomia de relações de subordinação entre personagens negras e brancas nas ilustrações, mas prevalecendo de forma explícita ou velada, relações de subordinação nas tramas. Além disso, a ideia de diversidade proposta pelos livros do acervo acentuou hierarquias sobre o "personagem, branco, sem deficiência" (VENÂNCIO, 2009, p. vi) como representante da espécie nos contextos dos livros analisados.

E o estudo de Veridiana Cintia de Oliveira (2010), também investigando o PNBE de 2008 (mas destinado à educação infantil), teve como objetivo "analisar como estão configuradas as relações entre brancos e negros na literatura infanto-juvenil distribuída pelo PNBE em 2008 para Educação Infantil" (OLIVEIRA, V.C., 2010, p. 11). A autora constatou em seus resultados que embora tenha sido possível identificar, ainda que em baixa frequência, um aumento de representação positiva de negras/os, personagens brancas continuam sendo mais bem elaboradas e aparecem mais vezes nas narrativas, gerando o "estabelecimento da manutenção do seu grupo como norma social e pressupondo inclusive, que os leitores presumidos sejam também brancos" (OLIVEIRA, 2010, p. viii). 
Também investigando a literatura destinada à educação infantil, a pesquisa de Gilmara Aparecida Guedes dos Santos Dadie (2013) analisou o protagonismo negro no acervo de uma biblioteca de uma escola de educação infantil (EMEI) em São Paulo. A autora investigou livros oriundos do PNBE e de aquisições por parte da própria prefeitura de São Paulo. Com 1.500 títulos disponíveis no acervo, apenas 33 livros tinham tal característica. Assim, a pesquisa constatou sub-representatividade em ambas as distribuições de livros, além de estereótipos em relação a personagens negras, bem como manifestações explícitas e implícitas de preconceito. Mas também foi possível identificar várias obras que abordaram positivamente valores culturais e estéticos africanos e afro-brasileiros.

Apenas uma pesquisa representa outro grupo identificado nessa categoria: que investiga como obras literárias podem conter referenciais positivos do ponto de vista da representação de personagens negras e ou da construção da identidade negra. Trata-se da pesquisa de Lucilene Costa e Silva (2012), cujo objetivo foi investigar representações sociais positivas em obras com temática africana e afro-brasileira, "em busca de novos referenciais estéticos e culturais para a construção da identidade da menina negra" (SILVA, 2012, p. xii). Por meio da análise de conteúdo e de categorias relacionadas com a corporeidade, a cultura afro-brasileira, a religião dos orixás e a questão de gênero, a autora investigou três livros publicados nas duas últimas décadas: "Betina", de Nilma Lino Gomes; "Omo-Obá: histórias de princesas", de Kiusam de Oliveira; e "Núbia rumo ao Egito", de Maria Aparecida Silva Bento. Sua constatação foi de que as obras analisadas reúnem um conjunto de elementos positivos acerca da menina negra nas narrativas o que pode contribuir, no espaço escolar, para o fortalecimento da identidade de meninas negras leitoras. $\mathrm{O}$ cabelo foi um marcador de destaque nos textos por centralizar ou problematizar a discussão sobre a identidade negra feminina.

E, ainda, outro grupo investigou, em contextos escolares, a recepção da leitura de obras com personagens negras. Foi o caso da pesquisa em que analisei os discursos de crianças e professoras, produzidos com base em leituras de obras literárias com personagens negras, em turmas de $4^{\mathrm{a}}$ série ${ }^{4}$ do Ensino Fundamental em duas escolas de Curitiba - PR (ARAUJO, 2010). A análise do contexto sócio-histórico da produção literária infantil e juvenil brasileira por meio do PNBE e dos acervos disponíveis nas bibliotecas das escolas e salas de aula, bem como e, sobretudo, da gravação de aulas de leitura, possibilitaram a constatação de que a ideologia racista operou nos estágios de produção, difusão e principalmente recepção da leitura das obras literárias. No entanto, ao lado

4 Nas duas escolas onde essa pesquisa aconteceu, a nomenclatura das turmas ainda não era de $5^{\circ}$ ano, como previam as mudanças na legislação educacional. 
dos limites no processo de mediação da leitura por parte de uma professora, também foram identificados avanços no trato de questões sobre estética e cultura africana, já que a alteridade estimulada pelo discurso da professora possibilitou às crianças ferramentas para a produção de interpretações mais positivas acerca das personagens negras.

Também neste mesmo grupo está a pesquisa de Juliana Maria C. F. Winter (2012), cuja investigação incidiu sobre práticas pedagógicas e o trato com a literatura. Seu objetivo foi analisar "como o emprego da literatura infanto-juvenil na perspectiva da Lei 10.639/2003, pode favorecer práticas pedagógicas que estabeleçam o diálogo e a reflexão sobre a discriminação racial e a diversidade cultural na sala de leitura" (WINTER, 2012, p. xiii). A autora analisou entrevistas com estudantes e professora da sala de leitura, e realizou de observações das aulas e análise de documentos de uma escola municipal de Petrópolis - RJ. E em tal investigação, Winter constatou que a escola promove ações de valorização da diversidade cultural. Sobretudo a postura pedagógica da professora investigada foi destacada pela autora, pois teria sido responsável por produzir posicionamentos críticos por parte das/os estudantes.

Divergindo da autora, no entanto, foi possível observar em seu estudo uma tendência de supervalorização das práticas pedagógicas da escola por meio, sobretudo, das ações desenvolvidas pela professora da turma investigada. Nas passagens em que estudantes comentam as leituras literárias com temática africana ou afro-brasileira, alguns discursos evidenciaram muitos limites da escola no encaminhamento de casos de discriminação racial e fragilidade pedagógica no trato de temáticas relacionadas à cultura africana. Muitas vezes, essa fragilidade incorreu em uma tendência de exotizar elementos culturais presentes nos livros selecionados para as aulas.

Também compondo o grupo de pesquisas que investigaram a recepção da leitura, mas destoando dos demais que direcionaram suas investigações para crianças do Ensino Fundamental, a pesquisa de João Martos Rosa (2013) foi desenvolvida com estudantes de $3^{\circ}$ ano do Ensino Médio de uma escola estadual, localizada em um município do interior do Mato Grosso do Sul. Teve como objetivo analisar quais representações as/os estudantes faziam da obra $O$ mulato, de Aluísio de Azevedo e que tipo de identidades negras podem ser construídas ao lerem tal romance. Rosa (2013) identificou que os estudantes negros do grupo participante da pesquisa tenderam a não se declararem negros em função das representações sociais típicas que incidem sobre seus pertencimentos étnico-raciais. E isso se refletiu nas interpretações que fizeram do livro lido: não se identificaram com o protagonista da obra, pois, além de ser negro, seu desfecho na trama sugeriu que sua vida não foi bem-sucedida. Os discursos oscilaram entre o mito da democracia racial e a culpabilização do 
próprio negro pela discriminação sofrida. Mas também houve uma tendência de identificar a sociedade, a cultura e a mídia pela reprodução de discriminações via veiculação de imagens negativas, contribuindo para a discriminação racial e para a estratégia do negro de não se assumir como tal. Por outro lado, o autor também reconheceu que a literatura trabalhada em sala de aula pode estimular reflexões mais críticas sobre a temática racial e fortalecer, desde que com esse objetivo e tendo professoras e professores preparados, a construção de identidades negras positivas.

E observando os dados quantitativos acerca das pesquisas aqui elencadas, constata-se, no período delimitado de 2003 a 2014, o ano predominante da produção como sendo 2012, com cinco pesquisas: duas teses (VIEIRA; SOUZA) e três dissertações (FERREIRA; WINTER; SILVA). Em 2010 foram três dissertações (ARAUJO; OLIVEIRA, V.C.; FIGUEIREDO) e em 2013 mais duas (DADIE; ROSA). Nos demais anos, foram defendidas apenas uma tese (SILVA, 2007) ou uma dissertação por ano (OLIVEIRA, 2003; VENÂNCIO, 2009).

As regiões brasileiras de onde provieram as teses e dissertações foram: Centro-Oeste, Nordeste e Sudeste, com três trabalhos cada, e Sul, com quatro. No que se refere às instituições, da Universidade Federal do Paraná procedeu o maior número de trabalhos: Venâncio (2009), Araujo (2010) e Oliveira (2010), sendo todas dissertações e orientadas pelo mesmo docente. Em seguida está a Universidade de São Paulo com duas dissertações (FERREIRA, 2012; DADIE, 2013), tendo diferentes orientadoras. As demais instituições que tiveram apenas um trabalho cada uma foram: uma dissertação pela Universidade do Estado da Bahia (OLIVEIRA, 2003), uma tese pela Universidade Federal do Rio Grande do Norte (SILVA, 2007), uma dissertação pela Universidade Federal da Grande Dourados (FIGUEIREDO, 2010), uma tese pela Universidade Federal do Ceará (VIEIRA, 2012) e outra pela Universidade Federal de Santa Catarina (SOUZA, 2012); uma dissertação pela Universidade Católica de Petrópolis (WINTER, 2012), uma pela Universidade de Brasília (SILVA, 2012) e uma pela Universidade Católica de Brasília (ROSA, 2013). Entre os trabalhos catalogados nessa categoria, somente a dissertação de Oliveira (2003) teve co-orientação.

\section{Considerações finais}

De modo geral, os resultados sobre a literatura (excetuando-se os textos e autores de época) apontam para mudanças, ainda que diminutas, na representação de personagens negras, com menos tendência a estereótipos raciais 
(VENÂNCIO, 2009; OLIVEIRA, 2010) e valorização da estética negra (FIGUEIREDO, 2010). No entanto, no universo geral dos acervos, ainda se pode categorizar as personagens negras em condições de sub-representação, além de uma reiteração da branquidade normativa (VENÂNCIO, 2009; OLIVEIRA, V.C., 2010) operando tanto na melhor elaboração de personagens brancas, como na pressuposição de leitoras e leitores brancos. Também foi possível observar, pelos resultados das pesquisas, que quanto mais antiga seja a obra, maiores são as chances de conter estereótipos negativos e racismo implícito ou explícito. Tal resultado foi demonstrado especialmente por Oliveira (2003) ao identificar que, embora em obras publicadas entre 1979-1989 tenha havido inovação ao se atribuir o papel principal a personagens negras, tal procedimento incorreu por outro lado na reificação de representações estereotipadas por meio da associação de protagonistas à miséria, à violência, a contextos de humilhação ou exotizados por seus atributos físicos.

Outro resultado negativo foi constatado por Araujo (2010) e relaciona-se à artificialidade no encaminhamento de práticas de leitura de obras com temática afro-brasileira e africana, reiterando uma ainda dificuldade em transposição do discurso legal (da legislação para a Educação das Relações Étnico-Raciais) para as práticas pedagógicas. Por outro lado, o empenho de professoras/es - ainda que em minoria nas escolas - em desenvolver práticas de leitura com temáticas da diversidade étnico-racial têm promovido reflexões sobre culturas africanas e da diáspora (WINTER, 2012; ARAUJO, 2010).

Outro estudo em particular (SOUZA, 2012) evidenciou a necessidade de ampliação dos referenciais literários e culturais para a produção de autoras/es negras/es em outros países, como Moçambique e Estados Unidos, como forma de identificação de características comuns aos povos da diáspora: a oralidade, a musicalidade e a valorização da tradição, por exemplo.

Em relação aos estudos da categoria "análise literária", por terem objetos de pesquisa diversificados e muitos deles analisando contextos históricos do passado (em especial a transição entre o século XIX e XX), não é possível identificar resultados em comum. Enquanto Ferreira (2012) reconheceu dubiedade na postura pública de José Alencar, que ora defendia a escolarização de escravizados e ora reiterava a omissão e despreocupação das elites brasileiras com o tema, Silva (2007) evidenciou o quanto o engajamento social de Lima Barreto não se restringiu à temática racial, mas também à condição da mulher e de outros grupos minoritários.

Um elemento emergente que se realçou em algumas pesquisas é a constatação de que se, as políticas públicas não assumem tal demanda, o impacto na escola tem sido bastante significativo: no contexto de sala de aula, sobretudo no tocante à recepção da leitura de obras com temáticas africanas e afro-brasileiras, 
por parte de estudantes predominaram resultados negativos já que a maioria das pesquisas identificou resistência e aversão a personagens negras, realçando o papel que as formas simbólicas como a literatura exercem na formação identitária dos grupos sociais (ARAUJO, 2010; WINTER, 2012; ROSA, 2013). E esse contexto evidenciou outro elemento emergente nas teses e dissertações: a necessidade de que o trabalho com literatura seja precedido de formação adequada de mediadoras/es de leitura, em especial professoras e professores, pois o acúmulo de conhecimentos e estratégias para o enfrentamento do racismo no discurso pedagógico (que é produzido também por estudantes) possibilitará um campo mais propício de recepção da literatura para além do cânone.

Como consequência, mudanças nas representações sociais poderão ocorrer, embora fique evidente que toda a problemática em torno do racismo nas representações sociais não se restrinja ao campo literário, mas pode ser um início de um processo de efetiva democratização que se iniciaria pela literatura. E ao mesmo tempo em que se revela como emergente, o processo de recepção da leitura de obras literárias por parte de estudantes apresenta-se como uma lacuna no campo de modo geral, pois, como demonstrado neste texto, apenas três dissertações investigaram em contextos escolares a recepção da leitura de obras e as práticas pedagógicas decorrentes ou não de tais leituras. A grande maioria fez análises endógenas, ou seja, o livro pelo livro.

Mais do que evidenciar o racismo, o estereótipo, estigmatização ou a valorização da cultura africana e afro-brasileira ou, ainda, a beleza estética e literária nos enredos e nas ilustrações, o que os resultados dessas poucas pesquisas demonstraram é a necessidade de investigação de como o público leitor, principalmente em formação, interpreta tais obras e quais as possibilidades de ampliação dos referenciais de mundo. Acrescenta-se o caso da educação infantil que pouco foi considerada, tanto nas análises sobre o livro como, de modo algum, na recepção por parte das crianças. Quais são as crianças que protagonizam as obras destinadas à criança pequena? E como as crianças pequenas leem as obras literárias? Essas questões unem-se a outras oriundas dos estudos da infância e que vêm denunciando a omissão das pesquisas acadêmicas sobre as vozes das crianças pequenas.

Outra lacuna dos estudos em nível de mestrado e doutorado é a biblioteca (da escola ou não) e sua relação com as obras literárias com temática africana ou afro-brasileira. Foi constatado brevemente por Venâncio (2009) e Araujo (2010), por exemplo, que é uma prática presente em algumas escolas manter livros novos guardados. Como ficam, então, os livros com temáticas da diversidade? Onde ficam e quem os lê? Da mesma forma, não houve estudos que investigaram como se dá (e se há) formação para bibliotecárias/os e mediadoras/es 
de leitura sobre temas concernentes à Educação das Relações Étnico-Raciais e, por extensão, à literatura não canônica.

Além disso, em relação às categorias gerais do projeto "Educação das Relações Étnico-Raciais: o estado da arte", foram apenas 13 estudos que investiram pesquisa sobre LIJ, demonstrando o baixo investimento acadêmico em pesquisas sobre as relações étnico-raciais na literatura para crianças e jovens. Torna-se preponderante uma ampliação do campo e para outras perspectivas, sob o risco de os estudos sobre a produção literária infantil e juvenil tornarem-se estagnados no apontamento para soluções.

\section{REFERÊNCIAS}

ARAUJO, D. C. de. Relações raciais, discurso e literatura infanto-juvenil. 2010. Dissertação (Mestrado em Educação) - Universidade Federal do Paraná, 2010.

COELHO, N. N. Literatura infantil: teoria, análise, didática. São Paulo: Moderna, 2000.

COELHO, N. N. Dicionário crítico da literatura infantil e juvenil brasileira. 5. ed. rev. atual. São Paulo: Companhia Editora Nacional, 2006.

DADIE, G. A. G. dos S. Personagens negros, protagonistas nos livros da educação infantil: estudo do acervo de uma escola de educação infantil do município de São Paulo. 2013. Dissertação (Mestrado em Educação) - Universidade de São Paulo, 2013.

FERREIRA, F. de J. "A redenção do corpo e da alma": a representação literária da educação dos escravizados em José de Alencar (1850-1875). 2012. Dissertação (Mestrado em Educação) - Universidade de São Paulo, 2012.

FIGUEIREDO, L. A. A criança negra na literatura brasileira: uma leitura educativa. 2010. Dissertação (Mestrado em Educação). Universidade Federal da Grande Dourados, 2010.

GOUVÊA, M. C. S. Imagens do negro na literatura infantil brasileira: análise historiográfica. Educação e Pesquisa, São Paulo, v. 31, n. 1, p. 77-89, jan./abr. 2005.

OLIVEIRA, M. A. de J. Negros personagens nas narrativas literárias infanto-juvenis brasileiras: 1979-1989. 2003. Dissertação (Mestrado em Educação) - Universidade do Estado da Bahia, 2003.

OLIVEIRA, M. A. de J. Personagens Negros na Literatura Infanto-Juvenil no Brasil e em Moçambique (2000-2007): entrelaçadas vozes tecendo negritudes. 2010. Tese (Doutorado em Letras) - Universidade Federal da Paraíba, 2010. 
OLIVEIRA, V. C. de S. de. Educação das relações étnico-raciais e estratégias ideológicas no acervo do PNBE 2008 para educação infantil. 2011. Dissertação (Mestrado em Educação) - Universidade Federal do Paraná, 2011.

ROSA, J. M. Representações de negros produzidas por alunos, mediadas pela leitura da obra "O Mulato". 2013. Dissertação (Mestrado em Educação) - Universidade Católica de Brasília, 2013.

ROSEMBERG, F. Literatura infantil e ideologia. São Paulo: Global, 1985. (Teses; 11).

SILVA, J. R. da. A educação da mulher em Lima Barreto. 2007. Tese (Doutorado em Educação) - Universidade Federal do Rio Grande do Norte, 2007.

SILVA, L. C. E. Meninas negras na literatura infantojuvenil: escritoras negras contam outra história. 2012. Dissertação (Mestrado em Educação) - Universidade de Brasília, 2012.

SOARES, M. A escolarização da literatura infantil e juvenil. In: EVANGELISTA, A. A. M.; BRANDÃO, H. M. B.; MACHADO, M. Z. V. (Org.). Escolarização da leitura literária: o jogo do livro infantil e juvenil. 2. ed., 2. reimp. Belo Horizonte: Autêntica, 2006. p. 17-48. (Linguagem e Educação).

SOUZA, R. F. de A. de. Khilá (des)encontros da voz na travessia Brasil-Moçambique. 2012. Tese (Doutorado em Educação) - Universidade Federal de Santa Catarina, 2012.

VENÂNCIO, A. C. L. Literatura infanto-juvenil e diversidade. 2009. Dissertação (Mestrado em Educação) - Universidade Federal do Paraná, 2009.

VIEIRA, L. C. F. Omeros: vozes de identidade cultura em Derek Walcott. 2012. Tese (Doutorado em Educação) - Universidade Federal do Ceará, 2012.

WINTER, J. M. C. F. Griot na escola: o emprego da literatura africana e afro-brasileira em uma sala de leitura. 2012. Dissertação (Mestrado em Educação) - Universidade Católica de Petrópolis, 2012.

Texto recebido em 29 de dezembro de 2017. Texto aprovado em 30 de dezembro de 2017. 